University of Nebraska - Lincoln

DigitalCommons@University of Nebraska - Lincoln

$7-2006$

\title{
Becoming the Harvard Man: Person-Environment Fit, Personality Development, and Academic Success
}

\author{
Peter D. Harms \\ University of Nebraska - Lincoln, pharms@gmail.com \\ Brent W. Roberts \\ University of Illinois, Urbana-Champaign, bwrobrts@illinois.edu \\ David Winter \\ University of Michigan
}

Follow this and additional works at: https://digitalcommons.unl.edu/managementfacpub

Part of the Management Sciences and Quantitative Methods Commons

Harms, Peter D.; Roberts, Brent W.; and Winter, David, "Becoming the Harvard Man: Person-Environment Fit, Personality Development, and Academic Success" (2006). Management Department Faculty Publications. 46.

https://digitalcommons.unl.edu/managementfacpub/46

This Article is brought to you for free and open access by the Management Department at DigitalCommons@University of Nebraska - Lincoln. It has been accepted for inclusion in Management Department Faculty Publications by an authorized administrator of DigitalCommons@University of Nebraska - Lincoln. 
Published in Personality and Social Psychology Bulletin 32 (July 2006), pp. 851-865; doi: 10.1177/0146167206287720

Copyright ( $\odot 2006$ by the Society for Personality and Social Psychology, Inc. Used by permission.

Preparation of this article was supported by a grant from the National Institute of Aging (R01 AG21178).

The authors thank Thomas Srull for his helpful comments on the preparation of this article.

\title{
Becoming the Harvard Man: Person-Environment Fit, Personality Development, and Academic Success
}

\author{
P. D. Harms \& Brent W. Roberts \\ University of Illinois, Urbana-Champaign
}

\author{
David Winter \\ University of Michigan
}

\begin{abstract}
The continuity and change of the needs and evaluations of the college environment and person-environment fit (PE fit) with the college environment were studied in a 4-year longitudinal study of students $(\mathrm{N}=191)$. Perceptions of the environment changed more dramatically than corresponding self-perceived needs. PE fit demonstrated moderate levels of consistency over the 4-year span, but no significant increases in mean levels were found over time. Antecedents to PE fit in the college environment included both intelligence and openness to experience. Outcomes associated with PE fit included changes in personality traits linked to openness to experience and higher academic achievement. The implications of the findings for personality development and the relationship of PE fit to successful outcomes are discussed.
\end{abstract}

Keywords: person-environment fit, personality, development, performance

Traditionally, psychologists have attempted to understand the causes of human behavior from two dominant perspectives. On one hand, social psychologists have emphasized the role of situational demands as a cause of behavior but have ignored the role of individual differences. On the other hand, personality researchers have focused their research on the role of traits, motives, and goals in shaping behavior and have paid little attention to the surrounding context. More recently however, there have been substantial efforts made to integrate these two perspectives by looking at role of both situations and individual differences conjointly. Beyond this, researchers have been called to investigate the feedback relationships that may exist between personality and social settings over time to better understand the interaction of these two determinants of behavior (Roberts \& Pomerantz, 2004). One approach to better understanding how social settings and personality interact to shape behavior is the person-environment fit (PE fit) approach.

A long-standing assumption of organizational researchers has been that individuals who share values with their organization will be more committed and more successful operators within that organizational context (Kristof, 1996). This match of attributes of individuals and attributes of the environments they operate in reflects the concept of PE fit (Caplan, 1987). Outcomes of PE fit have been hypothesized to range from psychological phenomena, such as personality consistency and satisfaction with the environment (Pace \& Stern, 1958; Roberts \& DelVecchio, 2000; Rounds, 1990), to better performance (Stern, 1970).

Beyond this, PE fit has been considered an important developmental construct because it reflects the manifestation of one of the primary goals of adulthood-to find one's developmental niche. Erikson (1968) argued that one of the goals of identity development is to find a 
niche that is uniquely suited for each individual. One's current identity is built through the acquisition of new social roles and shaping them to match one's dispositions, values, and abilities. These roles are inevitably manifest in organizations and institutions with which a person may fit more or less well. These organizations and institutions are selected in part because they are perceived to fit well with a person's needs. Even if an organization does not fit perfectly with one's needs, people will attempt to shape their experiences to maximize fit. Thus, PE fit represents a critical development phenomenon because it reflects in part the result of the efforts to find a niche that fits with one's current identity (Roberts \& Caspi, 2003).

\section{The Conceptualization and Measurement Person-Environ- ment Fit}

Conceptualizing and measuring PE fit is dependent on two critical features (Caplan, 1987). First, both the environment and the person must be considered jointly, and corresponding units of measurement must be used in the analysis. That is, the measures used to assess the attributes of both the person and the environment should be scaled in the same way so as to allow direct comparison. Second, the attributes of the person and the environment being assessed must match in an appropriate way. If the needs of the individual are being assessed, the resources provided by the environment should be measured in a commensurate fashion (O'Reilly, Chatman, \& Caldwell, 1991). Likewise, if an individual's abilities are being assessed, then the commensurate demands of the environment should be assessed (Kristof, 1996).

The components of PE fit, the person and the environment, can be assessed both subjectively and objectively, with each method providing unique information about fit (Caplan, 1987). The subjective person can be assessed through self-ratings of personal qualities while the nature of the objective person can be derived through aggregate judgments of peers or experts rating the target (Hofstee, 1994). Similarly, the subjective environment can be measured using self-reports of the nature of the environment while the objective environment can be assessed through consensual judgments of the environment (Stern, 1970). Subjective environment is akin to Murray's (1938) concept of beta press, whereas the concept of the objective environment reflects Murray's alpha press.

Continuity and Change of Environmental Presses, Individual Needs, and Person-Environment Fit Over Time

The assumption of many socialization models is that cultural presses remain constant over time (Jones, 1983).
Theoretical arguments have been made for why one's environment is likely to remain fixed over time. It is important for the characteristics of an organization to remain constant or else it would be difficult for individuals to select an organization that fit them well or adapt to an organization's characteristics (Shivy, Rounds, \& Jones, 1999). Assessments of university environments using the environmental assessment technique have shown moderate to high stability over 1- to 5-year periods (Gottfredson \& Richards, 1999).

However, there is to our knowledge no study that systematically measures both the consistency and the mean-level change of an organization's environmental press over time in a way so as to make it directly comparable with the amount of consistency and change seen in needs reflective of that press. Given the implicit acceptance of the socialization model by many researchers (Simmering, Colquitt, Noe, \& Porter, 2003), the question as to whether individuals tend to change their view of themselves or their view of the environment is clearly relevant to the understanding of how individuals come to fit with their environments.

There is also a surprising lack of longitudinal research focusing on the continuity and change in needs. Despite the lack of focus on needs, there are longitudinal and cross-sectional aging studies of analogous constructs, such as goals and interests. In a longitudinal study of gifted students, Nichols (1967) found that interests tended to become more specific and distinct over time, which resulted in an overall mean decrease in interests (Nichols, 1967). Presumably, if needs work the same way as interests and students come to understand better what they do and do not want out of an organization over time, their overall profile of need endorsement should go down with time (see also, Roberts, O'Donnell, \& Robins, 2004). However, we would expect that by narrowing the focus of one's needs, a few will exhibit significant increases.

It is generally assumed by many models of PE fit that a person's needs will change to fit with the characteristics of the organization over time through the process of socialization (Kristoff, 1996). That is, due to role expectations and the constant cultural press of the environment, individuals should respond to the presses of the environment by changing their needs to reduce stress. This would presumably result in increasing PE fit over time. However, Chatman (1991) found no significant meanlevel change over the course of 1 year in a sample of accountants. Likewise, Roberts and Robins (2004) found very little evidence of significant increases in PE fit in a university environment over 4 years.

Although there has been much speculation as to the developmental trends we would expect to see in PE fit over time, little research has actually been conducted to 
test the developmental trends. Roberts and Robins (2004) found moderate consistency in PE fit in their longitudinal study. Test-retest correlations over a 4-year time span ranged from .26 to .49. Chatman's (1991) study of accountants found a 1-year test-retest correlation of .62.

\section{Person-Environment Fit and Personality Development}

When relating personality development to PE fit, one must take into account both socialization and selection effects (Miech, Caspi, Moffitt, Wright, \& Silva, 1999; Roberts \& Robins, 2004). Socialization effects refer to the effects that experiences and events have on personality change. Selection effects refer to stable characteristics that individuals bring to an environment that may allow them to function more optimally in that environment. Because selection effects necessarily occur prior to socialization, it makes sense to test for selection effects prior to testing for effects of socialization.

It was argued by Chatman (1991) that fit is specific to each environment. That is, the qualities that make for good fit in one organizational context do not necessarily imply that those qualities will relate to fit in other contexts. For example, the organization studied in Roberts and Robins (2004) was seen as an achievementoriented, competitive, and unsupportive environment. Subsequently, the three best predictors of PE fit were high cognitive ability, low agreeableness, and high emotional stability. Other environments would be expected to show a different pattern of relationships between PE fit and personality.

In terms of socialization effects, PE fit should relate in a corresponsive fashion to personality over time. Specifically, the characteristics that a person brings to an environment that cause high fit are also likely to be the characteristics demanded by the environment and in turn are the characteristics that will change over time (Roberts, Caspi, \& Moffitt, 2003). For example, in the Roberts and Robins (2004) study, PE fit was predicted by disagreeableness and emotional stability. In turn, high PE fit was associated with increases in disagreeableness and emotional stability.

\section{Person-Environment Fit and Successful Functioning}

There is some evidence that PE fit may lead to better performance in achievement contexts such as work (Caplan, 1987) and school (Eccles et al., 1993; Pervin, 1968). For instance, Thistlewaite (1959) demonstrated that matches between the subject matter emphasized at a college and the interests of individual students resulted in higher rates of productivity and hours of study by students. However, tests of the relation between PE fit and performance based on the Holland system of in- terests have yielded mixed results (Holland, 1997). More targeted assessments of matching motivational orientation to learning environments have demonstrated positive results with performance in school settings (Harackiewicz, Barron, Tauer, \& Elliot, 2002). These researchers demonstrated that although performanceapproach goals were unrelated to interest in subject matter, they were linked to better performance in terms of grades at a competitive school. That is, individuals with an achievement orientation that matched the demands of the setting tended to act in such a way that they succeeded without necessarily becoming more invested, an outcome not demanded by the environment.

These previous studies have demonstrated that there may be a relationship between PE fit and the degree to which someone is satisfied and successful in the context of a job or organization. Unfortunately, to date there have been no prospective longitudinal studies demonstrating that the development of PE fit over time is related to the development of satisfaction and success in an organization over time.

\section{Prior Research and the Current Study}

Although there has been a great deal of speculation regarding the relationship of $\mathrm{PE}$ fit to personality development, little research has tested this in a longitudinal setting. The exception to this is a 4-year longitudinal study conducted by Roberts and Robins (2004) wherein various aspects of PE fit and its relationship to personality development were investigated in a university setting. PE fit was assessed using a short descriptive measure of the university environment that asked students to describe the characteristics of an ideal university environment and to what degree these characteristics were descriptive of their current campus. Spearman rank order correlations were then computed between the ideal and real descriptions of the university environment to create a PE fit measure. Analyses from this study revealed that PE fit demonstrated moderate rank order stability and little or no increases in mean levels over time. Furthermore, gender, cognitive ability, and personality traits predicted high PE fit in the college. In turn, higher levels of PE fit were associated with systematic changes in specific personality traits.

Although the Roberts and Robins (2004) study addressed basic issues surrounding PE fit and personality development, there remains a need for both replication and extensions of this research. In the present article, we sought to replicate, extend, and improve on this design in several ways. Similar to their previous study, we examined change and continuity of PE fit over time and tested the antecedents and consequences of PE fit for personality change over time. 
Our first improvement was to use a more comprehensive and thorough assessment of needs associated with the college environment. Specifically, the present study makes use of the Stern Activities Index (SAI) and the College Characteristics Index (CCI; Stern, 1970). These measures have been widely used to assess fit in the college environment and were specifically developed to address issues surrounding PE fit (Pace \& Stern, 1958; Stern, 1958). Second, the present study uses these measures to assess the degree to which the two components of PE fit, namely, individual needs and environmental perceptions, change over time. That is, students rated themselves and the school using these indexes both in their 1st and 4th years of college. Third, the present article will address issues surrounding the relationship of PE fit with performance outcomes in addition to personality development.

The assessment of the changes in the perceptions of the individual's environment is of particular interest in the current study. Individuals may change their perceptions of their environment for a number of reasons. For example, their expectations about the organization may be proven inaccurate, and new information causes them to correct their perceptions (Major, Kozlowski, Chao, \& Gardner, 1995). Alternatively, individuals may undergo a change in their social role whereby their environment, or at least the salient components of that environment that the individual interacts with, changes (Roberts et al., 2003). For instance, as an individual moves from freshman to senior in a university environment, different aspects of that environment may be interacted with more frequently or a different set of demands may be placed on that individual. More mundanely, the objective environment may actually change over time and the individual perceives this change. As the assessment of changing environmental perceptions remains relatively poorly documented, we believe that the assessment of such processes constitutes a major advance in the understanding of social adjustment and acculturation to new environments.

It should be noted that unlike previous published research, this study constitutes a unique sample and thus may provide unique contributions to the understanding of PE fit research. The present data come from an archival data set collected at Harvard University in the early 1960s of young men in the process of identity development. The environment of the university at that time has been characterized as a classical liberal arts education setting. Winter, McClelland, and Stewart (1981) studied the environment in great detail and concluded that the following seven factors characterized the university experience at that time: (a) academic involvement and contact with faculty, (b) encouragement of extracurricular activities, (c) dormitory-centered living arrange- ments, (d) cultural participation, (e) sports involvement, (f) voluntary service expectations and mentoring, and (g) a science orientation. These characteristics were reportedly an enduring aspect of the university and not specifically linked to the historical period when the data were collected. Therefore, we would expect that individuals characterized by intellectual pursuits and openness to ideas and experiences would be best suited to thrive in such an environment.

This research sets out to test the assumption of socialization models that although individuals may change, their environments exhibit stability over time. We will compare the mean levels of reported needs for both Years 1 and 4 to test the hypothesis that need endorsement will decrease over time. We test the hypothesis that PE fit will increase over time due to socialization pressures. We evaluate whether PE fit demonstrates comparable, moderate levels of consistency in PE fit over a 4-year time span as found in previous research. We evaluate the hypothesis that the antecedent personality predictors of PE fit match with the culture of the environment. We test the hypothesis that the needs that are antecedents to PE fit in this environment are in turn the needs that change the most over time in response to varying levels of PE fit. Finally, we test the hypothesis that higher levels of PE fit in the university environment are associated with greater success as defined by higher grades and higher levels of satisfaction.

\section{Method}

\section{Sample and Procedure}

The present study makes use of archival data from the Harvard Student Study (King, 1973) that was collected at Harvard University between the years 1960 and 1967. Participants were students entering the university in the years 1960 and 1961 and graduating in the years 1964 and 1965. Data from the remaining cohorts were not available for analysis. The sample under investigation was composed of 667 unmarried men who completed a variety of batteries, interviews, and experiments each year for the duration of their stay at Harvard. The sample demonstrated reasonably high average intelligence as assessed by SAT scores (average SAT scores ranged from 436 to $800, M=670, S D=64$ ).

The present study makes use of a subset of 191 students that completed all of the self-ratings and environmental assessments relevant to PE fit in both their 1st and 4 th years. A comparison was made using paired $t$ tests to evaluate whether our sample in their 1st year of school differed in any significant way from the students who did not participate over the 4 years. Each personal- 
ity scale under investigation and SAT scores were compared. Analyses indicated that for the 19 criteria under investigation, only 1 personality scale, the Brownfain Conscientiousness Scale showed any significant difference between the sample used and those not used. A paired samples $t$ test indicated that the mean of the sample group under investigation $(n=190, M=5.77, S D=$ 1.08) was significantly higher $(p \square \square .05)$ than those not included $(n=60, M=5.35, S D=1.02)$. This is approximately the number of differences we would expect by chance, so we can assume that our sample did not differ from their peers in any meaningful way as they entered school.

\section{Measures}

Person-environment fit. In the present study, we made use of measures designed to assess the needs of participants and matched them with conceptually parallel measures assessing the environment's capacity to meet those needs. To assess needs, students completed the Stern Activities Index. The SAI consists of 300 statements of commonplace, socially acceptable activities to which responses of like/dislike are given. These responses are used to assess individuals on 30 scales of 10 items each that correspond to 30 needs in Murray's taxonomy (Pace \& Stern, 1958). Examples of items in the SAI include "Learning more about the work of different painters and sculptors"; "Having lots of time to take care of my hair, hands, face, clothing, etc."; and "Keeping my room in perfect order." Reported reliabilities are moderate (KR-21s range from .25 to .85, $M \square .66) 1$ (Stern, 1970). It should be noted that this measure was designed to assess self-attributed or conscious needs as opposed to implicit needs (for a review, see McClelland, Koestner, \& Weinberger, 1989).

To assess environmental press, students rated their college environment according to a test conceptually matched to the SAI, the College Characteristics Index. The CCI consists of 300 statements about the college environment, making up 30 scales of 10 items each to which responses of true/false are given. The items themselves are statements about college life, such as curriculum, student organizations, teaching, and classroom activities (Pace \& Stern, 1958). Reported reliabilities for the CCI are moderate $(K R-21 \mathrm{~s}$ range from .26 to $.72, M=.54)$ (Stern, 1970). Examples of items in the CCI include "There are copies of many famous paintings in the (school) halls and (class) rooms and offices," "Students who are not neatly dressed (properly groomed) are likely to have this called to their attention," and "Classrooms are always kept neat and tidy." Table 1 has descriptions of the constructs being assessed in both the SAI and CCI. It should be noted that the items in the SAI scales reflect a preference for activities that are outward manifestations of the attempt to satisfy these needs. The CCI scales use items that are descriptive of an environment that would facilitate the satisfaction of these needs or promote the development of these needs.

The aggregate of the 30 environmental ratings from the CCI was used to derive a consensus evaluation of the environmental press that the university provided. Profile correlations of the subjective ratings of the 30 student needs and the subjective evaluation of 30 environmental presses were used to estimate beta fit. Profile correlations of the subjective ratings of the 30 student needs and the consensus, or objective, ratings of the 30 environmental presses of the university were used to estimate alpha fit. Positive scores indicate greater PE fit, or better matching of the person with the environment. Negative scores indicate less fit. Measures of fit were computed for both 1st and 4th years.

For consideration of the effects of the average PE fit an individual experienced over the duration of his tenure at college, the Year 1 and Year 4 measures of PE fit were averaged using Fisher's $r$-to- $z$ transformations to form a single average PE fit variable.

Academic ability. The average score that individuals received on the SAT before entering college was obtained through university records.

Academic performance. The average overall grade of participants was gathered from university records. The maximum possible overall grade was 12 points, with averages that ranged from 8.29 in the 1st year of school to 9.07 in the 4th year of school. Whether the student graduated with honors was also obtained through university records $(1=$ nonhonors graduation, $2=$ cum laude, $3=$ magna cum laude, 4 = summa cum laude).

Satisfaction with college life. Satisfaction was assessed with three questions about participants' relative level of satisfaction with Harvard. "What kind of time are you having at Harvard?" ( $1=$ very poor, $5=$ very good $)$, "How satisfied are you with your year at Harvard?" $(1=$ very unsatisfied, $4=$ very satisfied), and "Have you felt 'out of place' at Harvard?" ( $1=$ yes, most of the time, $4=$ never $)$. Standardized scores of these items were then combined to form a satisfaction measure for each year (average $=$ .70). An average satisfaction indicator was created by averaging the individual's scores across all 4 years $(\alpha=.81)$.

Personality. A variety of personality traits was assessed at Years 1 and 4.

The Myers-Briggs Type Indicator (MBTI), a 166-item multiple-choice test (Myers, 1962; Myers \& McCaulley, 1985) that is divided into eight personality dimensions 
Table 1. Scale Description for the Stern Activities Index and the College Characteristics Index

\begin{tabular}{|c|c|}
\hline Need/Press Scale & Description \\
\hline Abasement & The ready acknowledgement of inadequacy, ineptitude, or inferiority \\
\hline Achievement & Surmounting obstacles and attaining successful conclusions \\
\hline Affiliation & Gregariousness and group-centered associations with others versus social detachment \\
\hline Aggression & Indifference or disregard for the feelings of others as manifested in hostility, either overt or covert, direct or indirect \\
\hline Change & Variable or flexible behavior versus repetition and routine \\
\hline Counteraction & Persistent striving to overcome difficult, frustrating, humiliating, or embarrassing experiences and failures \\
\hline Deference & Respect for authority versus insubordination, rebelliousness, resistance, or defiance \\
\hline Dominance & $\begin{array}{l}\text { Ascendancy over others by means of assertive or manipulative control versus nonintervention, acceptance, } \\
\text { equalitartianism, permissiveness, humility, or meekness }\end{array}$ \\
\hline Ego achievement & $\begin{array}{l}\text { Idealistic social action, active or fantasied realization of dominance, power, or influence achieved through sociopolitical } \\
\text { activities in the name of social improvement or reform }\end{array}$ \\
\hline Fantasied achievement & $\begin{array}{l}\text { Daydreams of success in achieving extraordinary public recognition, narcissistic aspirations for fame, personal } \\
\text { distinction, or power }\end{array}$ \\
\hline Harm avoidance & $\begin{array}{l}\text { Fearfulness, avoidance, withdrawal, or excessive caution in situations that might result in physical pain, injury, illness, } \\
\text { or death versus careless indifference to danger, thrill seeking, boldness, venturesomeness, or temerity }\end{array}$ \\
\hline Humanities & The symbolic manipulation of social objects or artifacts through empirical analysis, reflection, discussion, and criticism \\
\hline Impulsiveness & Rash, impulsive, spontaneous, or impetuous behavior versus care, caution, or reflectiveness \\
\hline Narcissism & Vanity, aggrandizement, or egotism \\
\hline Nurturance & $\begin{array}{l}\text { Supporting others by providing love, assistance, or protection versus dissociation from others, indifference, withholding } \\
\text { support, friendship, or affection }\end{array}$ \\
\hline Objectivity & $\begin{array}{l}\text { Detached, nonmagical, unprejudiced, impersonal thinking versus irrational, paranoid, or otherwise egocentric } \\
\text { perceptions and beliefs }\end{array}$ \\
\hline Reflectiveness & Contemplation, introspection, preoccupation with private psychological, spiritual, esthetic, or metaphysical experience \\
\hline Science & The symbolic manipulation of physical objects through empirical analysis, reflection, discussion, and criticism \\
\hline Sensuality & $\begin{array}{l}\text { Sensory stimulation and gratification, voluptuousness, hedonism, preoccupation with esthetic experience versus } \\
\text { austerity, self-denial, temperance or abstinence, frugality, self-abnegation }\end{array}$ \\
\hline Sexuality & $\begin{array}{l}\text { Erotic heterosexual interest or activity versus the restraint, denial, or inhibition of such impulses, prudishness, } \\
\text { priggishness, asceticism }\end{array}$ \\
\hline Supplication & Dependence on others for love, assistance, and protection versus detachment and independence \\
\hline Understanding & Detached intellectualization, problem solving, analysis, theorizing, or abstraction as ends to themselves \\
\hline
\end{tabular}

was used as a proxy measure for four of the Big Five personality traits. According to John and Srivastava (1999), the dimensional measures from the MBTI capture four of the five domains of the Big Five. The Extraversion and reverse-scored Introversion scales were summed to create a single extraversion variable, the Feeling and reverse-scored Thinking scales were summed to create a single agreeableness variable, the Judging and reversescored Perceiving scales were summed to create a sin- gle conscientiousness variable, and the Intuition and reverse-scored Sensing scales were summed to create a single openness to experience variable.

Students also rated themselves on the Brownfain Self-Rating Inventory (Brownfain, 1952), which consists of 25 items rated on an 8 -point scale $(1=$ low, 8 $=$ high $)$. Big Five scale scores were computed from the Brownfain items based on data collected from a contemporary sample. ${ }^{2}$ Namely, 246 participants recruited 
from an introductory psychology class completed both the Brownfain Self-Rating Inventory and the Big Five Inventory (BFI; John \& Srivastava, 1999). Each of the Brownfain items was individually correlated with the five trait scores from the BFI. Items were retained for further analysis if they correlated most highly with one of the Big Five traits. Furthermore, Brownfain items were only selected if they correlated at least .20 with the BFI trait they were matched to for the self-referent rating. Results showed that the Brownfain contained items representing four of the five Big Five factors. The Extraversion Scale consisted of 4 items: cheerfulness, social poise, sociability, and popularity. The average alpha reliability of the Brownfain Extraversion Scale was $\alpha=.80$. The Agreeableness Scale consisted of 4 items: generosity, trustfulness, sincerity, and understanding of others. The average alpha reliability of the Brownfain Agreeableness Scale was $\alpha=.61$. The Conscientiousness Scale consisted of 4 items: neatness, consistency, initiative, and dependability. The average alpha reliability of the Brownfain Conscientiousness Scale was $\alpha=.58$. The Openness to Experience Scale consisted of 4 items: intelligence, general culture, selfunderstanding, and individuality. The alpha reliability of the Brownfain Openness to Experience Scale was $\alpha=$ .59. For the number of items in each scale, the reliabilities of each of these scales are at acceptable levels for further analysis.

Also included in the study was the Omnibus Personality Inventory (OPI; Heist \& Williams, 1957). The OPI was designed to assess attitudes, values, and interests thought to be relevant for their importance in understanding and differentiating among students in an academic setting. Six of the OPI scales were included in the present study. The Thinking Introversion (TI) Scale includes 60 items $(K R-21=.90)$ and is used to measure abstract thought and reflective thinking. The Theoretical Orientation (TO) Scale is composed of 32 items (KR$21=.74)$ that are designed to assess interest in science and scientific activities. High scorers are generally rational, logical, and critical in their approach to problems. The Estheticism (Es) Scale consists of 24 items $(K R-21=.80)$ and was designed to measure aesthetic values and diverse interests in artistic matters and activities. This scale includes items related to painting, sculpture, music, dramatics, and literature. The Complexity $(\mathrm{Co})$ Scale is 27 items long $(K R-21=.71)$ and reflects an experimental orientation. High scorers are tolerant of ambiguities and uncertainties and are fond of novel ideas and situations. The Impulse Expression (IE) Scale is 75 items long $(K R-21=.90)$ and denotes individual differences in the general readiness to express impulses and to seek gratification in conscious thought or overt action. The Originality (Or) Scale is 91 items long $(K R-21=.86)$ and is used to characterize individuals who love freedom of expression, have novel insights, and are independent in judgment. With the exception of the Impulse Expression Scale, the OPI scales included tend to reflect subfacets of the Big Five trait of Openness to Experience.

Due to a lack of data collection in the 1st year of the study, longitudinal comparisons using the OPI will be limited to Year 2 and Year 4 assessments.

To reduce redundancy across these personality measures, we ran a principal components analysis on the set of personality scales. A four-component solution offered the most parsimonious and best fitting solution, with the four components corresponding to extraversion, agreeableness, conscientiousness, and openness to experience. Component scores were generated using the means of the $z$ scores of the scales from the three measures of personality. The Brownfain extraversion and the MBTI extraversion and introversion scores were combined to create an extraversion scale. The Brownfain agreeableness combined with the MBTI feeling and thinking scores to create an agreeableness scale. It should be noted that the loadings for the Brownfain agreeableness scale were similar for both the conscientiousness and the agreeableness components. We based our decision to treat it as an agreeableness indicator based on research using the data from our contemporary sample. The Brownfain conscientiousness, OPI impulse expression (reversed), and the MBTI's judging and perceiving scores were combined to create a conscientiousness scale. The remaining scales from the OPI were combined with the Brownfain openness and the MBTI's intuition and sensing scores to create an openness to experience scale.

\section{Results}

\section{Environmental Press in the College Environment}

To evaluate what characteristics were most typical of the college environment and the amount of agreement about the importance of that characteristic in the environment, the mean level of each scale in the CCI along with its standard deviation are reported in Table 2. From the table, we can see that the most consistently high presses in the environment are reflectiveness, humanism, scientism, and understanding. These scales describe an environment that calls for contemplation, empirical analysis, the symbolic manipulation of objects, and detached intellectualization. This indicates that the dominant psychological theme of the institution was what personality psychologists would consider openness to experience, as the latter reflects openness to ideas and 
Table 2. Environmental Press as Measured by the College Characteristics Index

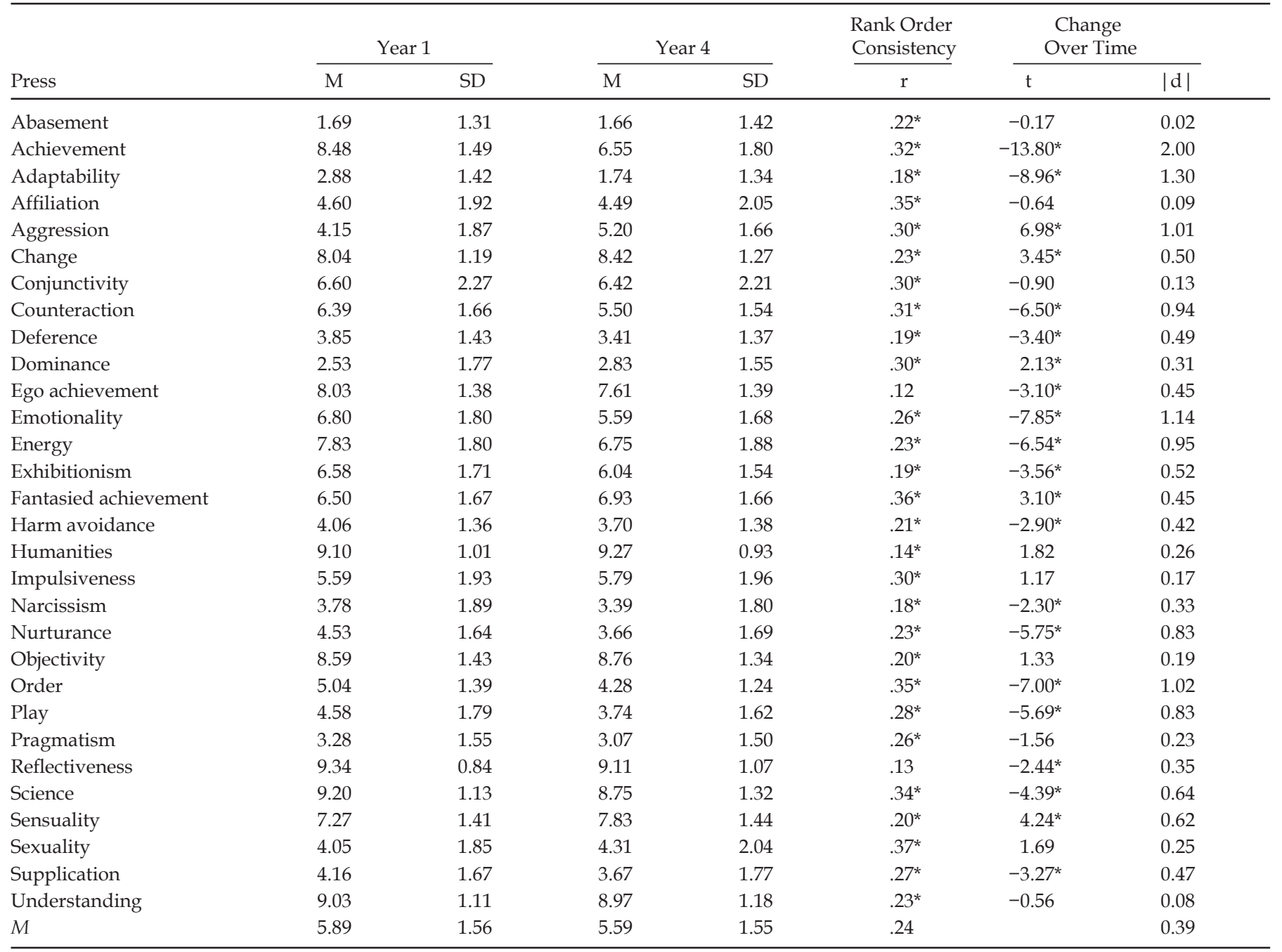

$N=191$

${ }^{*} p<.05$

a propensity for self-exploration and curiosity (McCrae, 1996). Therefore, we would expect that the openness to experience dimension would be most strongly related to PE fit in the present organization.

To understand the degree to which subjective perceptions of aspects of the environment are consistent across time, we correlated the Time 1 and Time 4 assessments of each of the CCI scales. As can be seen in Table 2, correlations between Time 1 and Time 4 assessments were significant for all but 2 of the 30 CCI scales, with press for ego achievement and press for reflectiveness failing to show marked consistency over time. Correlations of consistency ranged from .12 to .37 , with an average correlation of .24 .

Our expectation that perceptions of the college environment would remain relatively unchanged across the 4 years was not supported. We conducted paired $t$ tests of scores of the $30 \mathrm{CCI}$ scales collected at Time 1 and Time 4 to assess the degree to which subjective perceptions of the environment changed over time. As can be seen in Table 2, 21 of the scales showed significant change across the two time points. Namely, 5 of the scales increased over the 4 years: aggression, change, dominance, fantasied achievement, and sensuality. These scales broadly reflect agentic (Wiggins \& Trapnell, 1996) or approach-oriented (Keltner, Gruenfeld, \& Anderson, 2003) presses. Also, 16 scales showed decreasing perceptions of press strength across time. Interestingly, a contrasting change in environmental demands was seen whereby presses related to both ego enhancement (ego achievement, narcissism, and exhibitionism) and ego derogation (adaptability and supplication) showed decreases over time. Another interesting contrast was seen in that presses were perceived as de- 
Table 3. Individual Needs as Measured by the Stern Activities Index

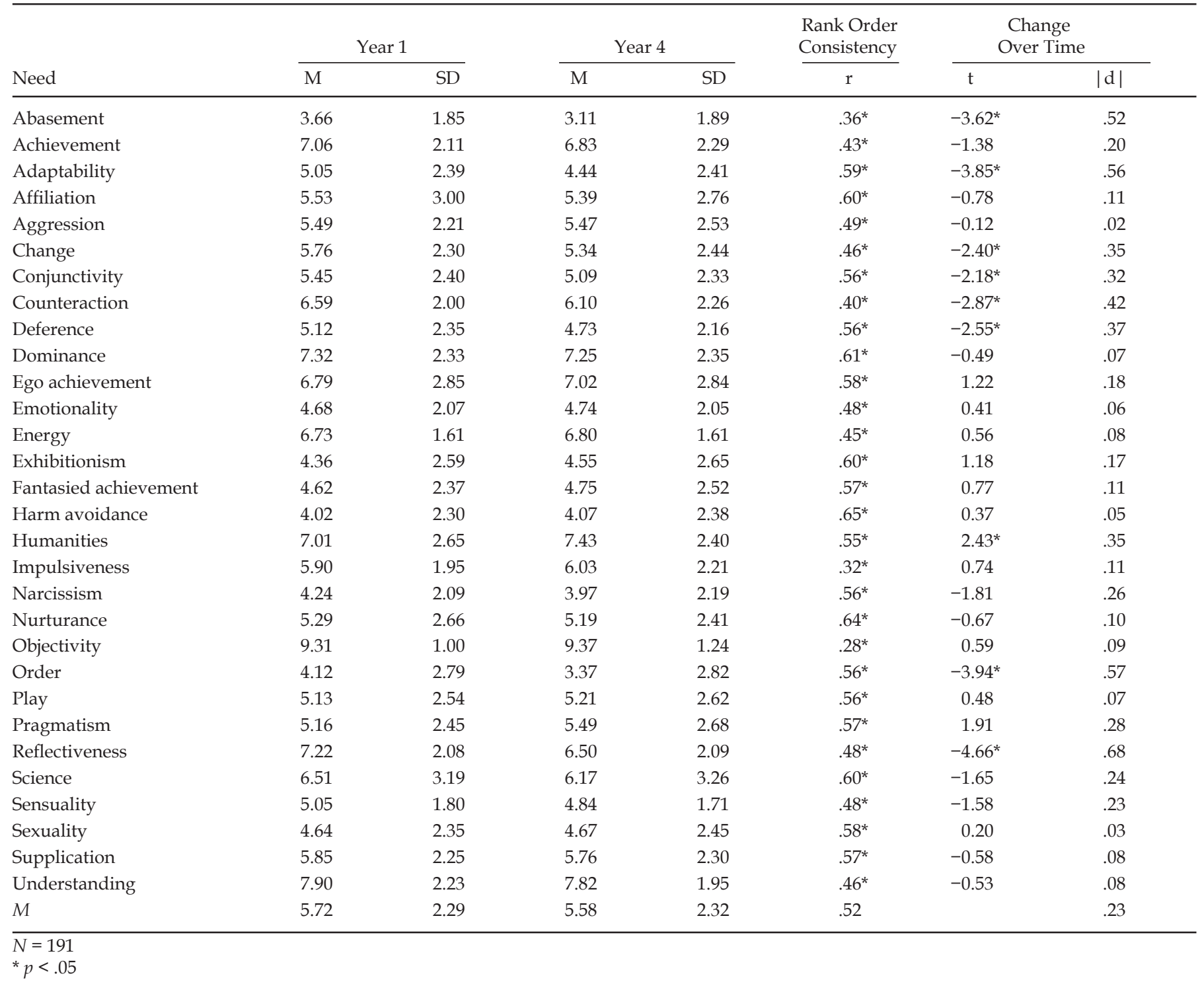

creasing for both leading an organized life (conjunctivity and order) and for pursuing more impulsive activities and fun (energy and play). Other presses that decreased over time were those associated with performance demands (achievement and counteraction) as well as harm avoidance, nurturance, reflectiveness, and scienticism. The absolute effect size (using Cohen's [1992] $d$ statistic) for change across time ranged from 0.02 to 2.00 and averaged 0.39. Finally, 9 of the 30 presses under investigation showed large effects for change over time.

\section{Individual Needs Among College Students}

To test whether individual differences in needs were consistent across time, scores from the Time 1 and Time 4 assessments of the SAI were correlated with one another.
As can be seen in Table 3, the correlations of needs ranged from .28 to .65 , with an average correlation of .52 .

We expected needs associated with the college environment to decrease as students clarified what it was they wanted from the organization. To assess the degree to which subjective perceptions of one's own needs changed over time, we conducted paired $t$ tests of scores of the 30 SAI scales collected at Time 1 and Time 4. As can be seen in Table 3, the results supported our hypothesis. Namely, 9 of the scales showed significant change across the two time points. Only 1 of the scales, humanism, showed a marked increase. The other 8 scales showed significant decreases over the 4-year period. Of particular note was the decrease seen in the need to self-deprecate or self-efface as shown by significant decreases in the Abasement, Adaptability, and Deference 
Table 4. Correlations of Alpha and Beta Fit Over Time

\begin{tabular}{lccccc}
\hline & \multicolumn{2}{c}{ Alpha Fit } & & \multicolumn{2}{c}{ Beta Fit } \\
\cline { 2 - 3 } \cline { 5 - 6 } & Year 1 & Year 4 & & Year 1 & Year 4 \\
\hline Year 1 alpha & - & & & \\
Year 4 alpha & $.57^{*}$ & - & & \\
Year 1 beta & $.85^{*}$ & $.47^{*}$ & & - \\
Year 4 beta & $.50^{*}$ & $.86^{*}$ & $.47^{*}$ & - \\
\hline$N=191$ & & & & \\
$*<<.05$ & & &
\end{tabular}

scales. Interestingly, there was a trend toward regulating behavior as seen in decreases in both the needs to behave spontaneously (change) and overregulate one's schedule (conjunctivity and order). That is, people seemed to be moving toward a more moderate level of what Block and Block (1980) referred to as ego control. Other decreasing needs included the need for counteraction and the need for reflectiveness.

\section{Continuity and Change in PE Fit Over Time}

We next tested the patterns of continuity and change in PE fit. To test for the degree of continuity of PE fit over time, we correlated the measures of alpha and beta fit taken at Year 1 and Year 4. Table 4 shows the correlations between the PE fit measures at both time points. Both forms of PE fit show moderate consistency across time with 4-year test-retest correlations ranging from .47 to .57 . These levels of consistency are comparable to those found for personality traits, which average .5 to .6 in the same age period (Roberts \& DelVecchio, 2000; Roberts \& Robins, 2004; Robins, Fraley, Roberts, \& Trzesniewski, 2001). These correlations are also slightly higher than previous estimates of PE fit consistency (e.g., Roberts \& Robins, 2004), which is most likely the result of the more exhaustive assessment of needs and environmental features found in the Stern system.

Next, the effects of socialization on PE fit were tested. According to socialization theories, mean levels of PE fit should increase with time spent in the environment. Paired $t$ tests were performed comparing Year 1 and Year 4 measures of PE fit. Neither alpha fit $(t=-.93, p$ $=.36, d=-.13)$ nor beta fit $(t=-1.78, p=.08, d=-.26)$ demonstrated any reliable, significant change over the course of 4 years.

\section{Personality as an Antecedent to PE Fit}

To determine what type of person was best matched with the college environment, we correlated antecedent ability and personality with average levels of PE fit (see
Table 5. Correlations Between Person-Environment Fit and Antecedent Personality Traits

\begin{tabular}{lcclll}
\hline \multirow{2}{*}{ Personality Trait } & \multicolumn{2}{c}{ Alpha Fit } & & \multicolumn{2}{c}{ Beta Fit } \\
\cline { 2 - 3 } \cline { 5 - 6 } Extraversion & $\mathrm{r}$ & $\beta$ & & $\mathrm{r}$ & $\beta$ \\
Conscientiousness & $-.27^{*}$ & $-.15^{*}$ & & $-.24^{*}$ & $-.14^{*}$ \\
Agreeableness & $-.23^{*}$ & $-.18^{*}$ & & $-.22^{*}$ & -.01 \\
Openness to experience & $-.24^{*}$ & -.00 & & $-.21^{*}$ & $-.15^{*}$ \\
SAT & $.58^{*}$ & $.52^{*}$ & & $.53^{*}$ & $.48^{*}$ \\
\hline$N=191$ & $.40^{*}$ & .12 & & $.35^{*}$ & .09 \\
${ }^{*} p<.05$ & & & & \\
& & & & &
\end{tabular}

Table 5). Given the consistent press for qualities such as reflectiveness, humanism, scientism, and understanding, we expected PE fit to be predicted by measures of openness to experience. Significant relationships with both types of PE fit were found at the zero-order correlation level for nearly every variable. To better differentiate the relationships between the antecedent traits and PE fit, we simultaneously entered the traits from each inventory along with SAT scores into a regression equation predicting PE fit, with separate equations being performed for each index. The results of these regressions are seen in Table 5. The most important antecedent for both types of PE fit is high openness to experience (alpha fit $\beta=.52, p<.05$; beta fit $\beta=.48, p<.05)$. Other significant antecedents of alpha fit included low extraversion $(\beta=-.15, p<.05)$ and low agreeableness $(\beta=-.18, p$ $<.05)$. Other significant antecedents of beta fit included low extraversion $(\beta=-.14, p<.05)$ and low agreeableness $(\beta=-.15, p<.05)$.

\section{Personality Development and PE Fit}

Given the strong predictive relationship between antecedent openness and PE fit, we expected that PE fit would be positively related to changes in openness over the 4-year period (e.g., corresponsive principle). To test whether PE fit was related to personality change, we regressed Year 1 variables onto corresponding Year 4 variables to test their unique contribution to development (see Neyer \& Asendorpf, 2001; Roberts, 1997; Roberts \& Bogg, 2004). That is, we predicted both Year 4 personality and Year 4 PE fit using personality and PE fit data collected at the beginning of the study. Figure 1 shows a representative model of the analytical procedure. The paths labeled $a$ and $b$ in the model reflect the paths representing the consistency in both PE fit and personality, respectively, over time. The paths labeled $c$ and $d$ reflect the prospective effects of PE fit on personality development and of personality traits on the development of later PE fit, respectively. The final relationship in the model, as indicated by $e$, reflects the correlation of the 


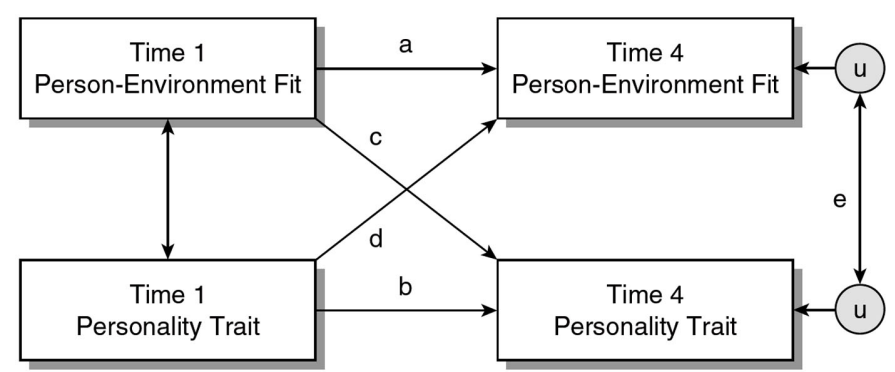

Figure 1. Conceptual and analytical model for analyzing the predictive and change relationships among person-environment fit and personality variables.

Table 6. Time 1 Personality Effects on Time 4 Person-Environment Fit (PE Fit) (Path $d$ in Figure 1)

Path From Initial Personality to Later PE Fit

\begin{tabular}{llcl} 
Personality Trait & Type of PE Fit & $\beta^{\mathrm{a}}$ & $\Delta \mathrm{R}^{2 \mathrm{~b}}$ \\
\hline Extraversion & Alpha fit & -.08 & .01 \\
& Beta fit & .05 & .00 \\
Conscientiousness & Alpha fit & $-.17^{*}$ & .03 \\
& Beta fit & $-.16^{*}$ & .02 \\
Agreeableness & Alpha fit & -.08 & .01 \\
\multirow{2}{*}{ Openness to experience } & Beta fit & -.11 & .01 \\
& Alpha fit & $.15^{*}$ & .02 \\
& Beta fit & $.23^{*}$ & .04
\end{tabular}

$N=191$

a Standardized beta in regression of later PE fit on initial PE fit and personality

${ }^{\mathrm{b}} R^{2}$ change from hierarchical regression analyses of later PE fit on initial PE fit (Step 1) and initial personality (Step 2)

${ }^{*} p<.05$

residuals of the two prior regression equations. That is, it reflects the correlation between the changes experienced in both PE fit and the personality trait being tested. This relationship represents the degree to which the changes occur in tandem with one another over time.

Of the cross-lagged paths in the model, only those labeled $d$, that is, those leading from Time 1 personality traits to later PE fit, demonstrated significant effects. The relationship whereby personality traits influenced the development of PE fit was significant only for conscientiousness and openness. Increased alpha fit over time was associated with lower conscientiousness $(\beta=-.17, p$ $<.05)$ and higher openness $(\beta=.15, p<.05)$. Increased beta fit was associated with lower conscientiousness ( $\beta$ $=-.16, p<.05)$ and higher openness $(\beta=.23, p<.05)$ as well. The results of these analyses can be found in Table 6. For the paths labeled $c$ in the model, that is, those leading from Time $1 \mathrm{PE}$ fit to later personality traits, none were significant.
Table 7. Correlations Between Change in Personality and Change in Person-Environment Fit

\begin{tabular}{lcc}
\hline Personality Trait & Alpha Fit & Beta Fit \\
\hline Extraversion & -.12 & $-.14^{*}$ \\
Conscientiousness & -.05 & -.03 \\
Agreeableness & -.02 & -.05 \\
Openness to experience & $.31^{*}$ & $.19^{*}$ \\
\hline$N=191$ & & \\
${ }^{*} p<.05$ & &
\end{tabular}

To test for a corresponsive relationship, the residuals of the previous regression analyses were correlated for each trait under investigation. These residuals represent change in the variable that cannot be attributed to initial PE fit or initial personality trait status. Thus, the change in PE fit over time was correlated with the change in a specific personality trait. The results of these analyses are presented in Table 7. In the present analyses, changes in openness were related to both alpha $(r$ $=.31, p<.05)$ and beta fit $(r=.19, p<.05)$. Correlated change was also seen in the relationship between extraversion and beta fit $(r=-.14, p<.05)$, albeit to a lesser degree. Thus, there was a moderately strong relationship between the changes seen in both openness and PE fit. This can be interpreted as evidence of a corresponsive relationship.

\section{PE Fit, Academic Success, and Satisfaction in the College Environment}

To assess the relationship between PE fit, academic success, and satisfaction in the college setting, we correlated average PE fit over 4 years with average overall grade, honors graduation, and overall satisfaction (see Table 8). Results of these analyses indicate that average PE fit was significantly related to school performance as measured by student rank for each year measures were available ( $r$ s ranged from .16 to .35$)$. Both alpha fit $(r=$ $.24, p<.05)$ and beta fit $(r=.19, p<.05)$ were significantly related to honors graduation. To compare the relative contribution of PE fit to performance, we regressed our performance outcomes onto average PE fit and SAT scores in a multiple linear regression (see Table 9). Results of these analyses show that both types of PE fit were related to academic performance in the 1st year of college beyond the effects of intelligence as assessed by SAT scores. Only alpha fit demonstrated significant relationships with academic performance in following 3 years, with standardized betas ranging from .16 to .20 . Contrary to our expectations, neither alpha fit $(r=-.06$, $p=.42)$ nor beta fit $(r=-.00, p=.99)$ was significantly related to overall satisfaction. 
Table 8. Correlations Between Person-Environment Fit, Academic Outcomes, and Satisfaction

\begin{tabular}{lcc}
\hline Outcome Indicator & Alpha Fit & Beta Fit \\
\hline Year 1 overall grade & $.35^{*}$ & $.32^{*}$ \\
Year 2 overall grade & $.28^{*}$ & $.20^{*}$ \\
Year 3 overall grade & $.27^{*}$ & $.20^{*}$ \\
Year 4 overall grade & $.23^{*}$ & $.16^{*}$ \\
Honors graduation & $.24^{*}$ & $.19^{*}$ \\
Overall satisfaction & -.06 & -.00 \\
\hline
\end{tabular}

n's range from 179 to 191

${ }^{*} p<.05$

\section{Discussion}

In this study we tracked the needs and environmental presses that make up the typical PE fit profile in a 4year longitudinal study of Harvard men. This is the first study to report relative levels of continuity and change in commensurate measures of needs and environmental presses. Interestingly, changes in the perceptions of the environment exceeded changes in self-reported needs. In addition, the derivative index of PE fit demonstrated moderate levels of consistency and no significant meanlevel change over time. Within the college environment being examined, individuals who experience fit with their environment were more intelligent and open to experience, specifically those aspects of openness that reflected reflective, abstract thinking and interest in science.

\section{Continuity and Change of Needs, Environmental Presses, and Person-Environment Fit Over Time}

We found several large changes for perceptions of the presses in the environment over time while the changes in corresponding needs were found less often and to a smaller degree. That is, people were more likely to change their perceptions of their environment than their self-perceptions. This is consistent with self-verification theory, which postulates that individuals are motivated to maintain a stable self-image to facilitate successful social relations and personal well-being (Swann, Stein- Seroussi, \& Giesler, 1992). These findings seem to contradict a widely held belief that individuals in the face of a powerful cultural press they cannot control will change themselves to make themselves fit better with the environment (Simmering et al., 2003). Furthermore, it opens up speculation regarding unidentified processes in the attraction-selection-attrition model (Schneider, 1987). Instead of changing their own characteristics and needs or simply leaving the organization, it seems that individuals are able to change the way they think about and ex-
Table 9. Multiple Regression of Person-Environment Fit and SAT Scores Predicting Academic Outcomes ${ }^{a}$

\begin{tabular}{llllll}
\hline & \multicolumn{2}{c}{ Alpha Fit } & & \multicolumn{2}{c}{ Beta Fit } \\
\cline { 2 - 3 } \cline { 5 - 6 } Outcome Indicator & Fit & SAT & & Fit & SAT \\
\hline Year 1 overall grade & $.23^{*}$ & $.29^{*}$ & & $.21^{*}$ & $.31^{*}$ \\
Year 2 overall grade & $.19^{*}$ & $.23^{*}$ & & .10 & $.27^{*}$ \\
Year 3 overall grade & $.20^{*}$ & $.17^{*}$ & & .14 & $.21^{*}$ \\
Year 4 overall grade & $.16^{*}$ & $.17^{*}$ & & .08 & $.21^{*}$ \\
Honors graduation & $.19^{*}$ & .14 & & .13 & $.17^{*}$ \\
\hline
\end{tabular}

$n^{\prime}$ 's range from 179 to 191

a All results presented are standardized betas

${ }^{*} p<.05$

perience the organization to suit their needs (Roberts, in press). Another possibility is that individuals changed their social roles over time. That is, as they moved from freshman to senior, the students changed the way in which they interacted with the environment and in turn how they perceived it. That individuals can be present in the same environment yet experience it quite differently has been explored previously in the context of a student's university experience. Winter et al. (1981) argued that individuals can engage various different niches or roles within the university environment and are therefore able to transform their experience of the university environment by magnifying some aspects of the environment and diminishing others. Still another possibility is that the environment really did change over time and individuals simply became aware of it.

The nature of the changes in perceived environment and in needs appeared quite consistent with the transition from 1st-year student to 4th-year veteran student and from neophyte to a person on the cusp of facing the world for the first time. Students found the university to be less playful, energetic, risky (harm avoidance), and introspective as they progressed toward graduation. In essence, the school moved from being fun to being a more sober and serious place. In contrast, the students found the university to become more hedonistic, aggressive, dominant, and focused on future achievement. These changes seem entirely consistent with the worldview of a graduating senior who has been readied for the world by an organization designed to afford one status and recognition. Changes in personal needs were less dramatic but in some ways very consistent with the changes in perceptions of the environment. Students found themselves less open to authority (reduced abasement, adaptability, and deference), indicating a willingness to take on the roles of leadership. In turn, they became less concerned with order, change, challenge, and the need for self-analysis (reflectiveness). Overall, these trends seem to point toward increasing psychological well-being as indicated by selfconfidence and ego control. 
To our knowledge, this is one of the first studies to track and report changes on dimensions of the environment and the person that were designed to be commensurate in nature. This makes the comparison of change more meaningful such that we can state with more confidence that perceptions of the environment changed more than personal needs. This finding has profound implications for our understanding of development as stereotypically, the environment has been portrayed as a stable influence on personality (e.g., Feldman, 1981).

\section{PE Fit and Personality Development}

We also tracked continuity and change in PE fit over time and how it related to personality development. The degree of continuity and level of change in PE fit is important for determining to what extent that construct is trait-like (Roberts \& Robins, 2004). In the present study, PE fit demonstrated similar levels of continuity to those of personality traits over a 4-year period (Roberts \& DelVecchio, 2000).

Consistent with previous findings (Roberts \& Robins, 2004), mean levels of PE fit did not show significant change over this period of time. We can conclude that the earlier findings were neither the result of using a brief measure of PE fit nor following a sample for a short time span. These findings provide additional evidence that there is little normative change in PE fit in response to increased exposure to an environment. Apparently, repeated experiences in that environment do not lead people to shift their needs toward the characteristics of the environment. However, given the moderate degree of consistency found in the PE fit indices over time despite no significant mean-level change, it seems reasonable to suggest that some individuals increased in PE fit while others decreased in PE fit over time.

The relationship between PE fit and personality development is best understood in terms of selection and socialization effects. It has been argued that the characteristics that are most responsible for an individual fitting well in a given environment are also the characteristics that are most valued in that environment (Chatman, 1991; Roberts \& Robins, 2004). In the present study, the constructs that best represented the organization in aggregate ratings of environmental press were those related to openness to experience, specifically, reflectiveness, understanding, scientism, and humanism. Consistent with this profile, we found that the personality traits most consistently related to high PE fit in the college environment were those that represented openness to experience, specifically, those traits that reflected abstract, reflective thinking and an interest in science.
The present study also investigated the corresponsive patterns of organization-person relationships over time. That is, we expected the traits that were most important for fitting in this context to match the traits that experienced the most change in response to the experience of high or low PE fit over time. Consistent with the corresponsive principle, we found that the traits most likely to change in tandem with changes in PE fit were those related to openness to experience. Thus, it is possible that the traits that tend to lead an individual to fitting well with an organization were enhanced by the experience of being in that organization and increased over time.

\section{PE Fit and Academic Success and Satisfaction}

Beyond its relationship to personality development, the value of PE fit as a construct has usually been linked to its relationship to performance and satisfaction within an organizational context. In the present study, PE fit demonstrated significant relationships with success as measured by academic performance. The strength of these relationships indicates that the match between an individual's own needs and those of the environment is an important construct to take into account when assessing predictors of performance over time.

Unlike previous studies of PE fit, we found no significant relationship between having a higher fit with one's environment and overall satisfaction within the context of that environment. This is perhaps not completely unexpected. Although the relationship between personenvironment congruence and satisfaction has long been a central tenet of the PE fit literature (Holland, 1997), there have been criticisms that this relationship is not as robust as originally thought (Tinsley, 2000). For example, a meta-analysis of person-environment congruence (Tranberg, Slane, \& Ekeberg, 1993) using the Holland model of assessing interests and environments found that there was evidence of high variability in effect sizes across studies. The authors of that study found that the mean correlation between PE fit and satisfaction in the college environment was .10. Furthermore, it was noted by Tranberg et al. (1993) that environments characterized by high investigative codes, much like the environment currently under investigation, demonstrated below average relationships between satisfaction and PE fit. Beyond this, the work of Harackiewicz et al. (2002) indicated that not all outcomes are necessarily associated with a particular kind of fit. If fitting into the environment meant having an open, academic orientation, we should expect that fit would in turn be related to academic success as indexed by grades and awards. However, if the fitting in had little or nothing to do with the enjoyment of the process, one would not expect fit to be linked to satisfaction in that context. Together, these findings seem to indicate 
that the lack of a significant positive PE fitsatisfaction relationship is not entirely surprising.

\section{Limitations, Future Directions, and Conclusions}

The results of the present study replicate and extend the results found in Roberts and Robins (2004) that demonstrated the relationships between the antecedents and outcomes of PE fit. In general, the findings support the idea that PE fit is not only an important construct in personality development but also plays a role in performance within the context it is relevant to. Despite this, the current study does have limitations that must be addressed.

First and foremost, the measures of personality used in this study did not tap the entire Big Five as they lacked any measure of the Big Five trait of Neuroticism. The lack of measurement of this trait domain limits the scope of traits assessed, which in turn limits the generalizability of our study. These oversights are however understandable in light of the fact that the data being analyzed are archival and the original data collection process was not designed with the Big Five in mind.

Another major concern is that of the PE fit indexes themselves. Although we were limited to specific combinations of PE fit due to the measures at hand, we acknowledge that a number of relevant combinations went untested. For instance, we had no truly objective measure of the environment to test against, so the perceptions of the participants were used instead. Beyond this, the components of the PE fit index were based on theoretical assumptions about the nature of students' personalities. Therefore, the possibility that the PE fit index was overly weighted for specific traits such as openness, which may have produced spurious or exaggerated results, remains a possibility. To address this concern, we hope that further research will be conducted that takes pains to use balanced measures that do not favor particular traits. Finally, because the two PE fit indices shared data origins on the person side of the equation, the indices produced markedly similar results. ${ }^{3}$ However, we believe that both the beta fit and alpha fit indices are still valuable for future research as the beta fit index reflects an individual's conscious understanding of his or her environment, whereas the alpha fit index may reflect fit in ways that the individual is not entirely aware of. Thus, although these indices are highly correlated in this study, they need not always be. Future researchers may also wish to go further and investigate the consequences of using peer reports of personality to generate a profile of the objective person to form a fit index.

Although this study found that one's impressions of the environment were more likely to change than one's own identity, we were unable to ascertain the source of these changes. Future research that takes into account selection effects and makes use of more waves assessment and more objective measures of the environment are needed to fully answer this question.

Despite the longitudinal nature of the current project, the causal direction of the correlational relationships is by no means easily determined. It should also be pointed out that these findings are based on a single sample of college students at an exceptional institution who are likely unrepresentative of college students. The current sample consisted of an all male group of students from middle- or upper-class backgrounds, virtually all of whom were Caucasians. Future research should make efforts to replicate these findings with the aim of exploring the nature of PE fit and personality development in students from minority backgrounds, women, and the socioeconomically disadvantaged.

In conclusion, the present study demonstrated that perceptions of the environment change dramatically over time, while at the same time personal needs associated with the university setting showed only modest changes. These changes seem to be due to a need for individuals to maintain a stable self-image while at the same time trying to find a way to adjust to their environment. In contrast, $\mathrm{PE}$ fit is a relatively stable construct that shows little mean-level change over time. In terms of the relationship between PE fit and personality development, we found that PE fit changed most in relationship with changes in traits in domains that are most relevant to fitting in with the context being evaluated. In addition, PE fit is relevant in the prediction of performance within the context being assessed. Few other psychological constructs demonstrate such breadth or potency in both personality and objective outcomes.

\section{Notes}

1. The results of this analysis were unchanged when the subscales of the Stern Activities Index with alpha reliability coefficients less than .60 were excluded from the person-environment fit index.

2. Thanks to Dustin Wood for collecting and analyzing this data.

3. It was pointed out by a reviewer that the alpha fit measure nearly always produces better results. We believe that this is true due to the elimination of individual biases and errors in the beta fit index.

\section{References}

Block, J. H., and Block, J. (1980). The role of ego-control and egoresiliency in the organization of behavior. In W. A. Collins (Ed.), Minnesota symposia on child psychology (Vol. 13, pp. 39-101). Hillsdale, NJ: Lawrence Erlbaum.

Brownfain, J. J. (1952). Stability of the self-concept as a dimension of personality. Journal of Abnormal and Social Psychology, 25, 597-606.

Caplan, R. D. (1987). Person-environment fit theory and organizations: Commensurate dimensions, time perspectives, and mechanisms. Journal of Vocational Behavior, 31, 248-267.

Chatman, J. (1991). Matching people and organizations: Selection and socialization in public accounting firms. Administrative Science Quarterly, 36, 459-484. 
Cohen, J. (1992). A power primer. Psychological Bulletin, 112, 155-159.

Eccles, J. S., Midgley, C., Wigfield, A., Buchanan, C. M., Reuman, D., Flanagan, C., et al. (1993). Development during adolescence: The impact of stage-environment fit on young adolescents' experiences in schools and in families. American Psychologist, 48, 90-101.

Erikson, E. H. (1968). Identity: Youth and crisis. Oxford, UK: Norton \& Co.

Feldman, D. C. (1981). The multiple socialization of organizational members. Academy of Management Review, 6, 309-318.

Gottfredson, L., and Richards, J. (1999). The meaning and measurement of environments in Holland's theory. Journal of Vocational Behavior, 55, 57-73.

Harackiewicz, J. M., Barron, K. E., Tauer, J. M., and Elliot, A. (2002). Predicting success in college: A longitudinal study of achievement goals and ability measures as predictors of interest and performance from freshman year through graduation. Journal of Educational Psychology, 94, 562-575.

Heist, P., and Williams, P. (1957). Manual for the omnibus personality inventory. Berkeley: University of California, Berkeley, Center for Study of Higher Education.

Hofstee, W. K. B. (1994). Who should own the definition of personality? European Journal of Personality, 8, 149-162.

Holland, J. L. (1997). Making vocational choices: A theory of vocational personalities and work environments. Odessa, FL: Psychological Assessment Resources.

John, O. P., and Srivastava, S. (1999). The Big Five trait taxonomy: History, measurement, and theoretical perspectives. In L. A. Pervin and O. P. John (Eds.), Handbook of personality: Theory and research (2nd ed., pp. 102-138). New York: Guilford.

Jones, G. R. (1983). Psychological orientation and the process of organizational socialization: An interactionist perspective. Academy of Management Review, 8, 464-474.

Keltner, D., Gruenfeld, D. H., and Anderson, C. A. (2003). Power, approach, and inhibition. Psychological Review, 110, 265-284.

King, S.H. (1973). Five lives at Harvard: Personality change during college. Cambridge, MA: Harvard University Press.

Kristof, A. L. (1996). Person-organization fit: An integrative review of its conceptualizations, measurement, and implications. Personnel Psychology, 49, 1-49.

Major, D., Kozlowski, S., Chao, G., and Gardner, P. (1995). A longitudinal investigation of newcomer expectations, early socialization outcomes, and the moderating effects of role development factors. Journal of Applied Psychology, 80, 418-431.

McClelland, D. C., Koestner, R., and Weinberger, J. (1989). How do self-attributed and implicit motives differ? Psychological Review, $96,690-702$.

McCrae, R. (1996). Social consequences of experiential openness. Psychological Bulletin, 120, 323-337.

Miech, R. A., Caspi, A., Moffitt, T. E., Wright, B. R., and Silva, P. A. (1999). Low socioeconomic status and mental disorders: A longitudinal study of selection and causation during young adulthood. American Journal of Sociology, 104, 1096-1131.

Murray, H. A. (1938). Explorations in personality. New York: Oxford University Press.

Myers, I. B. (1962). The Myers-Briggs type indicator. Princeton, NJ: Educational Testing Service.

Myers, I. B., and McCaulley, M. H. (1985). Manual: A guide to the development and use of the Myers-Briggs type indicator. Palo Alto, CA: Consulting Psychologists Press.

Neyer, F. J., and Asendorpf, J. B. (2001). Personality-relationship transaction in young adulthood. Journal of Personality and Social Psychology, 81, 1190-1204.

Nichols, R. C. (1967). Personality change and the college. American Educational Research Journal, 4, 173-190.

O'Reilly, C. A. III, Chatman, J., and Caldwell, D. F. (1991). People and organizational culture: A profile comparison approach to assessing person-organization fit. Academy of Management Journal, 34, 487-516.

Pace, C. R., and Stern, G. (1958). An approach to the measurement of psychological characteristics of college environments. Journal of Educational Psychology, 49, 269-277.
Pervin, L. A. (1968). Performance and satisfaction as a function of individual-environment fit. Psychological Bulletin, 69, 56-68.

Roberts, B. W. (1997). Plaster or plasticity: Are work experiences associated with personality change in women? Journal of Personality, $65,205-232$.

Roberts, B. W. (in press). Personality development and organizational dynamics across the life span. In B. M. Staw (Ed.). Research on organizational behavior. Greenwich, CT: JAI.

Roberts, B. W., and Bogg, T. (2004) A 30-year longitudinal study of the relationships between conscientiousness-related traits, and the family structure and health-behavior factors that affect health. Journal of Personality, 72, 325-354.

Roberts, B. W., and Caspi, A. (2003). The cumulative continuity model of personality development: Striking a balance between continuity and change in personality traits across the life course. In R. M. Staudinger and U. Lindenberger (Eds.), Understanding human development: Lifespan psychology in exchange with other disciplines (pp. 183214). Dordrecht, the Netherlands: Kluwer Academic Publishers.

Roberts, B. W., Caspi, A., and Moffitt, T. (2003). Work experiences and personality development in young adulthood. Journal of Personality and Social Psychology, 84, 582-593.

Roberts, B. W., and DelVecchio, W. F. (2000). The rank-order consistency of personality traits from childhood to old age: A quantitative review of longitudinal studies. Psychological Bulletin, 126, 3-25.

Roberts, B. W., O'Donnell, M., and Robins, R. W. (2004). Goal and personality development. Journal of Personality and Social Psychology, $87,541-550$.

Roberts, B. W., and Pomerantz, E. M. (2004). On traits, situations, and their integration: A developmental perspective. Personality and Social Psychology Review, 8, 402-416.

Roberts, B. W., and Robins, R. W. (2004). A longitudinal study of person-environment fit and personality development. Journal of Personality, 72, 89-110.

Robins, R. W., Fraley, C., Roberts, B. W., and Trzesniewski, K. (2001). A longitudinal study of personality change in young adulthood. Journal of Personality, 69, 617-640.

Rounds, J. B. (1990). The comparative and combined utility of work value and interest data in career counseling with adults. Journal of Vocational Behavior, 37, 32-45.

Schneider, B. (1987). The people make the place. Personnel Psychology, 40, 437-453.

Shivy, V., Rounds, J., and Jones, L. (1999). Applying vocational interest models to naturally occurring occupational perceptions. Journal of Counseling Psychology, 46, 207-217.

Simmering, M., Colquitt, J., Noe, R., and Porter, C. (2003). Conscientiousness, autonomy fit, and development: A longitudinal study. Journal of Applied Psychology, 88, 954-963.

Stern, G. (1958). Preliminary manual: Activities Index; College Characteristics Index. Syracuse, NY: Syracuse University Research Institute, Psychological Research Center.

Stern, G. (1970). People in context. New York: John Wiley.

Swann, W. B., Stein-Seroussi, A., and Giesler, R. B. (1992). Why people self-verify. Journal of Personality and Social Psychology, 62, 392-401.

Thistlewaite, D. L. (1959). College press and student achievement. Journal of Educational Psychology, 50, 183-191.

Tinsley, H. E. A. (2000). The congruence myth: An analysis of the efficacy of the person-environment fit model. Journal of Vocational Behavior, 56, 147-179.

Tranberg, M., Slane, S., and Ekeberg, S. E. (1993). The relation between interest congruence and satisfaction: A meta-analysis. Journal of Vocational Behavior, 42, 253-264.

Wiggins, J. S., and Trapnell, P. D. (1996). A dyadic-interactional perspective of the five-factor model. In J. S. Wiggins (Ed.), The five factor model of personality: Theoretical perspectives (pp. 88-162). New York: Guilford.

Winter, D. G., McClelland, D., and Stewart, A. (1981). A new case for the liberal arts. San Francisco: Jossey-Bass. 